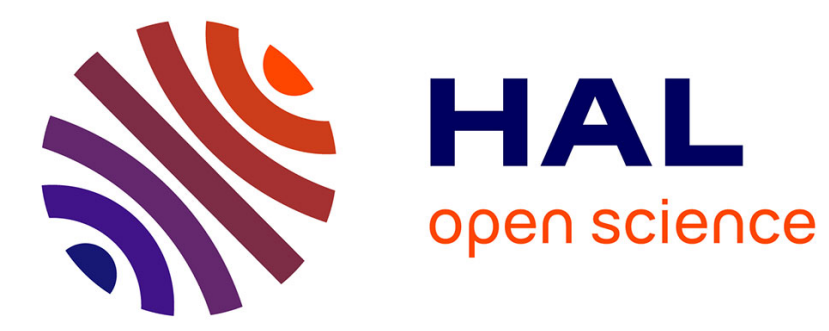

\title{
What accounts for good practice? Assessment of obesity prevention projects for kindergarten children in Germany
}

Jessica A. Dreas, Holger Hassel

\section{- To cite this version:}

Jessica A. Dreas, Holger Hassel. What accounts for good practice? Assessment of obesity prevention projects for kindergarten children in Germany. Journal of Public Health, 2009, 18 (2), pp.145-152. 10.1007/s10389-009-0285-2 . hal-00535293

\section{HAL Id: hal-00535293 \\ https://hal.science/hal-00535293}

Submitted on 11 Nov 2010

HAL is a multi-disciplinary open access archive for the deposit and dissemination of scientific research documents, whether they are published or not. The documents may come from teaching and research institutions in France or abroad, or from public or private research centers.
L'archive ouverte pluridisciplinaire HAL, est destinée au dépôt et à la diffusion de documents scientifiques de niveau recherche, publiés ou non, émanant des établissements d'enseignement et de recherche français ou étrangers, des laboratoires publics ou privés. 


\title{
What accounts for good practice? Assessment of obesity prevention projects for kindergarten children in Germany
}

\author{
Jessica A. Dreas • Holger Hassel
}

Received: 14 April 2009 /Accepted: 14 September 2009/Published online: 16 October 2009

(C) Springer-Verlag 2009

\begin{abstract}
Objective Up to now, no guideline has been set up that provides criteria for good practice in universal and selective childhood obesity prevention projects for children aged 3 to 6 in the kindergarten setting. Hence, based on guidelines for targeted prevention, the present study not only aims at assessing the current state of German universal and selective childhood obesity prevention projects in kindergartens, but also at deriving criteria of good practice in order to help fill this gap.

Methods An assessment of German childhood obesity prevention projects in the kindergarten setting was carried out by investigating prevention projects.

Results We identified 78 projects. It was not possible to find adequate information on all derived criteria at hand. We assessed the documentation in the databases as rather insufficient and fragmentary. Based on the documented data and the additional telephone inquiry, the identification of good practice projects seems rather difficult.

Conclusion The derived criteria are helpful to access universal and selective childhood obesity projects, but in the future the documentation in the databases needs to be
\end{abstract}

Electronic supplementary material The online version of this article (doi:10.1007/s10389-009-0285-2) contains supplementary material, which is available to authorized users.

\section{J. A. Dreas $(\bowtie)$}

Bremen Institute for Prevention Research and Social Medicine, Department of Public Health Medicine, Bremen University, Linzer Str. 10,

28359 Bremen, Germany

e-mail: dreas@bips.uni-bremen.de

H. Hassel

Department of Social Work and Health,

University of Applied Sciences,

Coburg, Germany augmented in order to increase project transparency and comparability.

Keywords Universal prevention · Selective prevention . Kindergarten $\cdot$ Children $\cdot$ Obesity

\section{Abbreviations}

AG 7 Forum Gesundheitsziele DeutschlandArbeitsgruppe 7: Gesund aufwachsen (Working area 7: Health Targets Germany)

BZgA Bundeszentrale für gesundheitliche Aufklärung (Federal Center for Health Education)

BLE Bundesanstalt für Landwirtschaft und Ernährung (Federal Agency for Agriculture and Food)

DBS Deutscher Bildungsserver (German Education Server)

DJI Deutsches Jugend Institute (German Youth Institut)

DPP Deutscher Präventionspreis (German Prevention Award)

KUG Kinder-Umwelt-Gesundheit (Children Environment and Health)

NICE National Institute for Clinical Excellence

PEB Plattform für Ernährung und Bewegung (Platform for Diet and Physical Activity)

RKI Robert Koch Institute

SIGN Scottish Intercollegiate Guidelines Network

WHO World Health Organization

\section{Introduction}

The prevalence of childhood overweight and obesity has currently increased in Germany (Kurth and Schaffrath Rosario 2007; Böhm et al. 2002). Recent reviews of 
obesity intervention projects underline the need to establish and expand prevention projects at an early stage. Childhood obesity prevention can be promising if health-related behavior and structural measures are incorporated into everyday life (Stice et al. 2006; Faeh 2006; National Institute for Health and Clinical Excellence 2006b). Moreover, prevention research shows that those overweight and obesity prevention projects in settings like kindergartens are most qualified that offer a broad spectrum of measures such as the improvement of eating behavior and the enhancement of physical activity (Stice et al. 2006; World Health Organization 2006a; Summerbell et al. 2005; Thomas PR 1995; Davis and Christoffel 1994). However, mandatory criteria to measure the qualification of kindergarten projects need to be developed.

The implementation of food literacy and physical activity in the kindergarten setting is beneficial as discussion and sensitizing can take place at an early stage. The kindergarten setting is central for learning and living. In Germany, $87.6 \%$ of children aged 3 to 6 attend a kindergarten (Forschungsverbund Deutsches Jugendinstitut and Dortmunder Arbeitsstelle Kinder- und Jugendhilfestatistik 2008).

Depending on the level of exposure with regard to different target groups, the World Health Organization divides prevention on the basis of a complementary specificity model differentiating universal, selective and targeted prevention. In doing so, multifactorial conditions of diseases can be taken into account (World Health Organization 2000). Table 1 shows target groups and goals of prevention depending on the degree of risk using the example of overweight and obesity in the kindergarten setting.

Obesity prevention projects focusing on universal and selective prevention can be well embedded in the kindergarten setting. Here, all children can be reached, and furthermore, special interventions for risk groups can be warranted (World Health Organization 2000; Gill 1997; Thomas PR 1995).

Contrary to guidelines for targeted childhood obesity prevention, there is currently no coherent and comprehensive guideline for universal and selective childhood obesity prevention by which contents and structure can be assessed and good practice projects concerning universal and selective prevention can be identified. The aim of the present study is to assess German universal and selective obesity prevention projects that were implemented in the kindergarten setting. For the assessment of the identified projects, we checked whether they fulfill eight criteria taken from guidelines for targeted prevention. We only selected criteria that can be used for universal as well as for selective guidelines, meaning criteria that do not consider aspects of treatment, i.e., criteria that focus on the study design, such as the duration of projects and the documentation of data.

\section{Methods}

Selection of criteria for the assessment of universal and selective childhood obesity prevention projects

According to the above-mentioned deficit, we selected criteria from already existing guidelines for targeted prevention in order to assess universal and selective childhood obesity prevention projects. Guidelines by the following institutions were considered: the Federal Center for Health Education (BZgA), National Institute for Clinical Excellence (NICE), Scottish Intercollegiate Guidelines Network (SIGN) (National Institute for Health and Clinical Excellence 2006a; Bundeszentrale für gesundheitliche Aufklärung 2005; Scottish Intercollegiate Guidelines Network 1996). These guidelines mainly focus on targeted prevention and

Table 1 Level of prevention based on the example of overweight and obesity in the kindergarten setting

\begin{tabular}{|c|c|c|}
\hline Level of prevention & Target group & $\begin{array}{l}\text { Goal (using the example of overweight and obesity prevention in the } \\
\text { kindergarten setting) }\end{array}$ \\
\hline Universal prevention & Entire kindergarten setting & $\begin{array}{l}\text { To reduce the incidence of new cases of overweight and obesity } \\
\text { To lower the incidence of obesity respectively to stabilize the level } \\
\text { of obesity } \\
\text { To reduce the mean weight, to optimize nutritional intake, to increase } \\
\text { physical activity and to decrease lifestyle-induced risk factors }\end{array}$ \\
\hline Selective prevention & $\begin{array}{l}\text { Potential risk groups: high-risk subgroups are } \\
\text { characterized by genetic, biological or other } \\
\text { factors (e.g., low socio-economic status or } \\
\text { children with obese parents) with an increased } \\
\text { risk of overweight and obesity }\end{array}$ & $\begin{array}{l}\text { To reduce the incidence of overweight and obesity: risk management, } \\
\text { if applicable, of weight stabilization; for further goals, see universal } \\
\text { prevention }\end{array}$ \\
\hline Targeted prevention & Obese children with a high-risk profile & $\begin{array}{l}\text { To prevent further weight gain, to reduce risks, meaning slow weight } \\
\text { reduction, if applicable }\end{array}$ \\
\hline
\end{tabular}

Federal Agency for Agriculture and Food (BLE) 2008; German Education Server (DBS) 2008; German Prevention Award (DPP) 2008 
insufficiently address universal and selective prevention as defined by the World Health Organization (WHO) because weight management strategies are mainly the focus here, and the projects are not carried out in settings like kindergartens. This should not be the case for universal and selective prevention (Spitzenverbände der deutschen Krankenkassen 2008; Bundeszentrale für gesundheitliche Aufklärung 2005). Therefore, we only considered those criteria that are relevant for this aim. With special regard to selective prevention, a guideline for health promotion for socially deprived families was kept in mind (Bundeszentrale für gesundheitliche Aufklärung 2006).

According to the definition of the WHO, projects that target weight loss cannot be defined as public healthorientated universal and selective prevention projects. Therefore, we ignored those in our assessment.

Taking into account guidelines for targeted prevention as well as one guideline for health promotion for socially deprived families, we chose the following criteria to assess universal and selective childhood obesity prevention projects:

(1) Target group: Children aged 3 to 6 years. The focus is on projects that basically address children from socially deprived families as well as children with a migration status because these groups are more often affected by overweight and obesity (Kurth and Schaffrath Rosario 2007; Müller et al. 2001).

(2) Contents of modules: The projects mainly focus on at least one of the following modules: food literacy, physical activity or the achievement of a healthy weight status (Summerbell et al. 2005).

(3) Parental participation: Parents are involved in the program and have the chance to participate (Bundeszentrale für gesundheitliche Aufklärung 2006).

(4) Goals: Specific goals of the program are mentioned (Bundeszentrale für gesundheitliche Aufklärung 2005).

(5) Duration of the project: The programme covers a period of at least 16 weeks. These relatively short projects with easily implementable intervention steps are successful according to a review of Stice et al. (Stice et al. 2006). It has to be taken into account that according to the transtheoretical model of change, modified behavior is to be considered stable after 24 weeks (Prochaska et al. 1996; Prochaska and DiClemente 1982).

(6) Manuals/ material: A manual with a minimum of one of the following contents is available: description of the program or background information or directions for further project materials (Bundeszentrale für gesundheitliche Aufklärung 2005).

(7) Documentation of data: The documentation of data is at hand (Bundeszentrale für gesundheitliche Aufklärung 2005).
(8) Evaluation: For quality improvement, an evaluation of the program concerning outcome or process evaluation is implemented (Summerbell et al. 2005).

For the search for appropriate projects we took three steps: First, we conducted a search in eight databases of the following institutions:

- the Federal Center for Health Education (BZgA) [Federal Centre for Health Education (BZgA) 2008], http://www.bzga.de

- Health Targets Germany: Working Area 7 (AG 7) [Health Targets Germany: Working Area 7 (AG 7) 2008], http://www.gesundheitsziele.de

- Platform Diet and Physical Activity (PEB) [Platform Diet and Physical Activity (PEB) 2008], http://www. ernaehrung-und-bewegung.de

- German Youth Institute (DJI) [German Youth Institute (DJI) 2008], http://www.dji.de/cgi-bin/projekte/output. php?projekt $=479$

- Federal Agency for Agriculture and Food (BLE) [Federal Agency for Agriculture and Food (BLE) 2008], http://www.ble.de/cln_099/DE/00_Home/ homepage node.html? nnn=true

- Children environment and health (KUG) [children environment and health (KUG) 2008], http://www. kinderumweltgesundheit.de

- German Prevention Award (DPP) [German Prevention Award (DPP) 2008], http://www.deutscher-praevention spreis.de

- German Education Server (DBS) [German Education Server (DBS) 2008], http://www.bildungsserver.de

Second, we performed a literature search in three databases, namely in Vascoda, Gepris and Medpilot. For the identification of appropriate projects, a set of provided keywords was used (see Appendix).

Third, we conducted telephone inquiries at the Robert Koch Institute (RKI), BZgA and PEB to identify further projects. For each project, we compiled a matrix including inter alia the above-mentioned criteria:

(1) Name of project

(2) Institution/contact person

(3) The project targets socially deprived families or families with migration background. Yes/no

(4) At least one of the following modules is taken into consideration: nutrition, physical activity, healthy body weight. Yes/no

(5) Level of prevention. Universal/selective

(6) Parental participation is included. Yes/no

(7) Goals of program are defined. Yes/no

(8) A draft concerning the contents of the program is available. Yes/no

(9) Duration of the project. Weeks/months/years 
Fig. 1 Considered projects versus hits in total

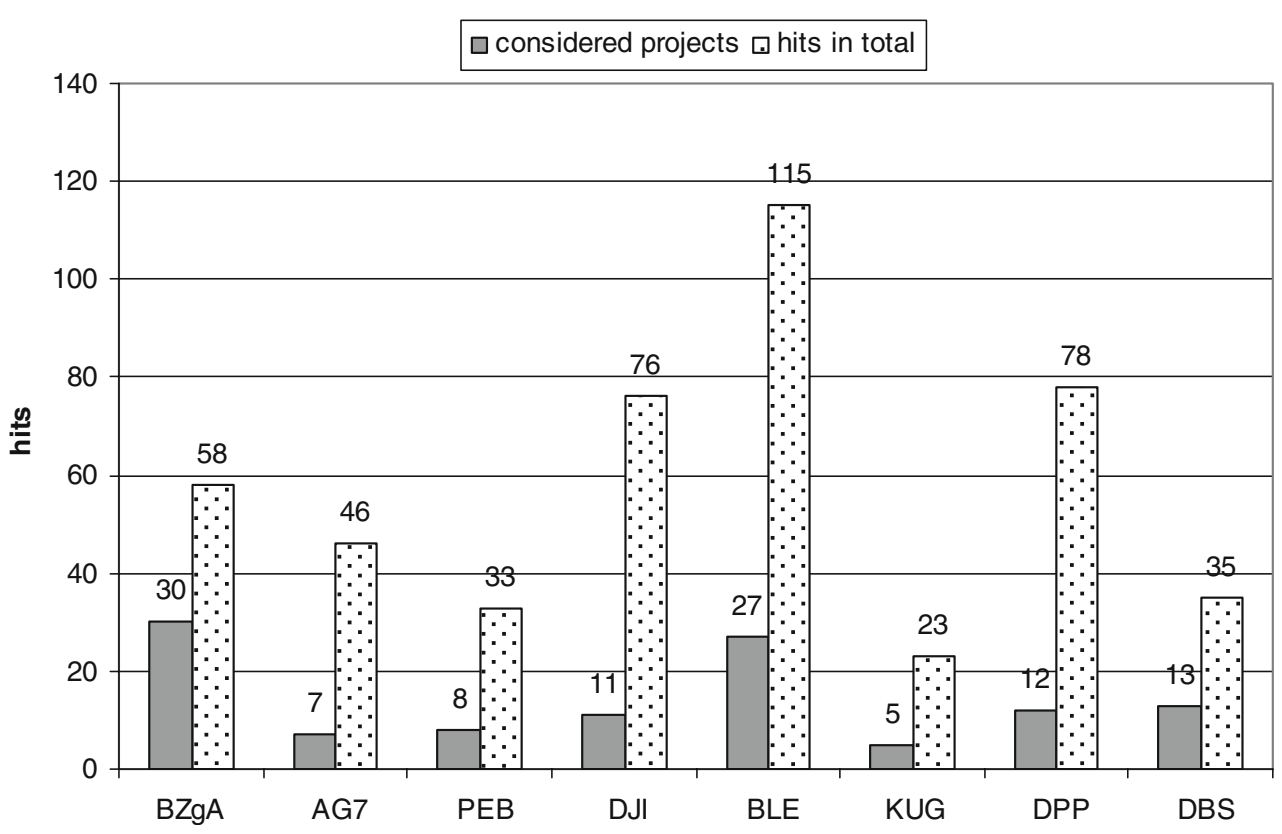

(10) Manuals/materials are available. Yes/no

(11) Documentation of data is provided. Yes/no

(12) Evaluation of data is provided. Yes/no

The search in the databases and the telephone inquiries showed that in 40 projects not all criteria were available at hand. In this case, we contacted the person in charge of each project, whose data were fragmentarily documented, via e-mail and asked them to comment on the missing criteria with yes/no responses. Overall, we registered 34 responders. The deadline ended 29 February 2008. All e-mails that arrived up to this date were compiled in the inquiry and added to the considered databases. Consequently, when "database" is mentioned in the following text, it is implied that also e-mail responders are accounted for.

\section{Results}

\section{Number of considered projects}

Altogether, 78 projects were found including all appropriate databases. Figure 1 shows a comparison of every hit per database, meaning that also projects for targeted prevention and other health promotion projects were found and the number of projects taken into account that fulfilled the criteria for universal and selective prevention. Due to an overlap of some projects, the black hits do not sum up to 78 .

Quantitative overview of results

We want to point out that "no information available" simply means that on the databases, respectively on the project homepages, no explicit indications to the corresponding criteria were made. This does not imply that this criterion was not taken into account in the project, but it could not be assessed.

Furthermore, it has to be noticed that while performing the comparison per database a different number of projects was taken as a basis, and, consequently, one project can be found in more than one database. According to each criterion the percentage refers to the totalities in eight different databases, meaning that eight different totalities are taken into consideration.

\section{Modules taken into account}

Figure 2 shows how many times each module was identified in all 78 projects. Furthermore, it indicates how the modules nutrition, physical activity and healthy body weight proportionally are distributed regarding all hits. Physical activity is the module noticed most often, followed by nutrition. Conspicuously, healthy body weight is mentioned least often.

Overview of quality criteria of projects

Figure 3 depicts the absolute frequency with which each criterion was mentioned in the various databases. How often every database indicates consideration of one of our defined criteria is assessed.

Low socio-economic status (SES) ${ }^{1}$ and migration background

An average of $43.3 \%$ of the projects address children with low socio-economic status and a migration background.

\footnotetext{
${ }^{1}$ Socio-economic status is defined by parental education, occupational status and family income (Bundeszentrale für gesundheitliche Aufklärung 2006).
} 
Fig. 2 Frequency of modules by projects (left) and frequency of modules by databases (right)

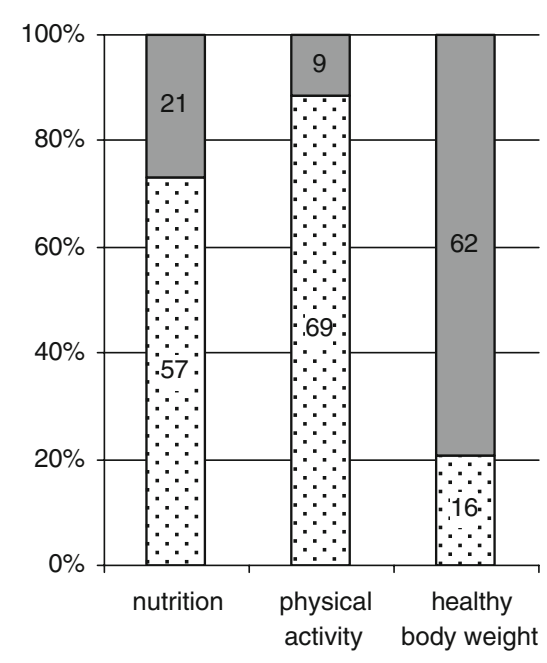

amodule considered $\square$ module not considered

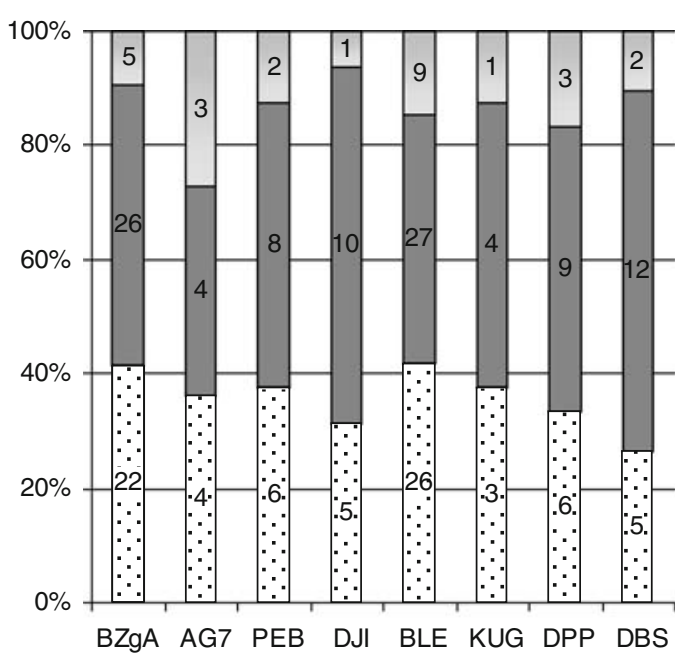

$\square$ nutrition $\square$ physical activity $\square$ healthy body weight
Seventy percent respectively $77 \%$ of the project databases of the BZgA and the BLE target children with low socioeconomic status and migration status. The databases Peb and KUG as well as the homepage of the "Deutscher Präventionspreis" (German Prevention Award, with regard to the projects of the years 2004 to 2007) refer to this group in half of their projects $(50 \%)$. In the database AG 7, only one project of a total of seven projects addresses socially disadvantaged families or families with migration status. Similar results are found in the databases DJI and DBS where $18.2 \%$ respectively $15.4 \%$ address children with migration status and low socio-economic status.
Level of prevention

Of the projects, $42.3 \%$ target universal prevention, meaning that all the children in the kindergarten setting are addressed. Altogether, $56.7 \%$ of the projects apply at the level of selective prevention, meaning that potential risk groups, e.g., socially deprived families or children with migration status, are addressed in the program.

Parental participation Of the projects, 95\% target parental participation. This refers to all databases.
Fig. 3 Quality criteria of projects

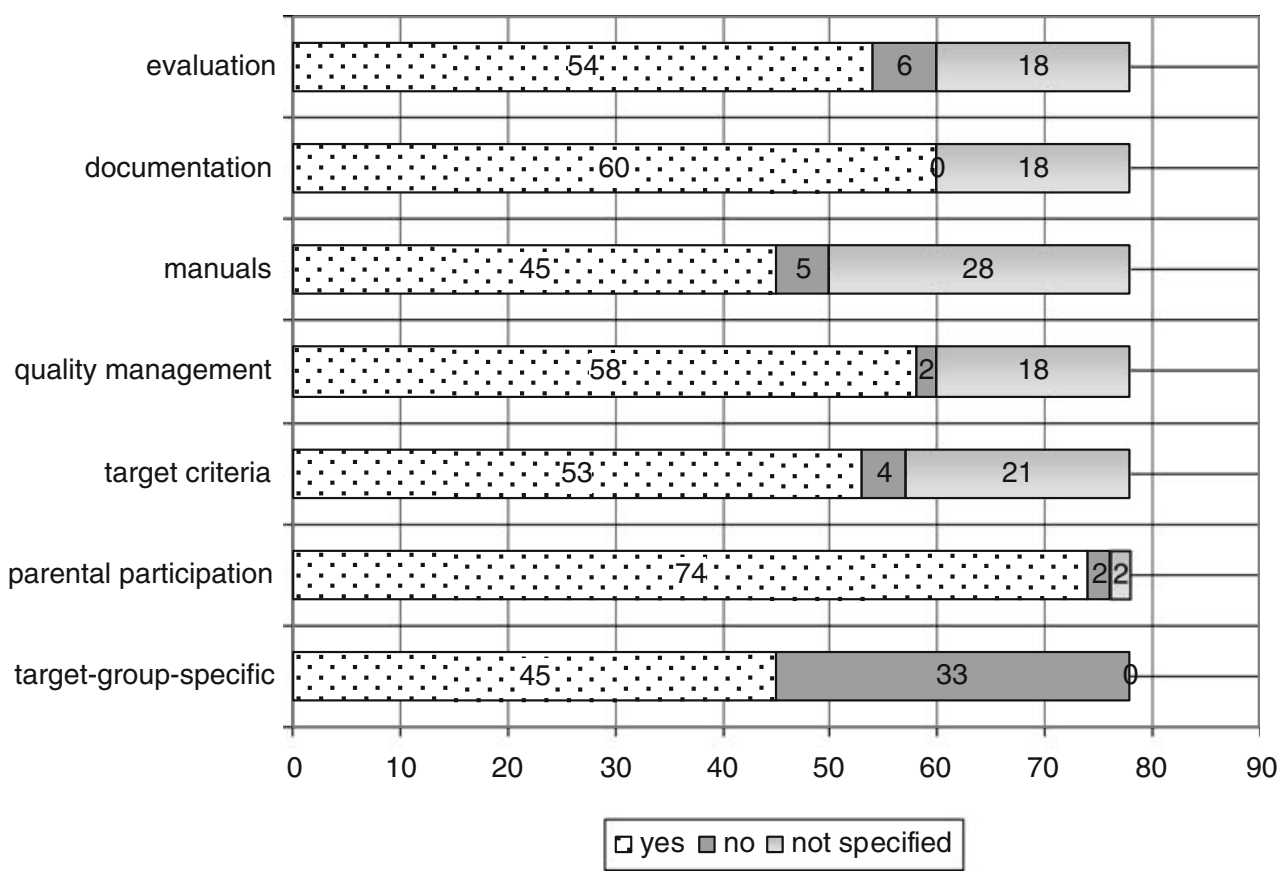


Concrete target criteria In total, $76.8 \%$ of all kindergarten projects have specific target criteria at hand. All kindergarten projects identified in the database KUG have such criteria; $90.9 \%$ of the projects found in the DJI database have target criteria as well as $91.6 \%$ of the projects in the DBS databases. The identified projects from the databases of the BZgA and the projects of the German Prevention Award mention 56.6\% respectively 58.3\% of the targeted criteria.

Quality management/written concept Regarding quality management, all the kindergarten projects found in the databases of PEB, DJI and KUG follow written concepts. So does the homepage of the "Deutscher Präventionspreis" (German Prevention Award (DPP) 2008) (83.3\%), as well as the database of the BLE (85.1\%). Referring to all databases, excluding the BZgA, more than $80 \%$ of the kindergarten projects have written concepts at hand. No information was available for $40 \%$ of the BZgA concerning written concepts.

Duration of projects Of the projects, $11.5 \%$ of those taken into account have intervention times of less then 2 years, and $23.1 \%$ last between 2 and 4 years. Only one project (1.3\%) has a duration of exactly 4 years. In $43.6 \%$ of the projects, no exact information was provided about the running time of the program. That means that the end of the program was not planned. In these cases, the notation "there is no prospect of an end" was most often found. For 20.5\% of the identified projects, no information was available about the running time.

Manual/material Of all databases, 67.8\% indicate using manuals and materials. Most projects that have manuals and materials were found in the database PEB: $87.5 \%$ of the kindergarten projects that were found in this database indicate having materials and manuals, whereas the minimum of projects $(46.6 \%)$ using materials and manuals was found in the database of the BZgA.

Documentation An average of $81 \%$ of the projects provide data documentation according to the information given in the databases respectively acknowledged via e-mail (BZgA 86.6\%, AG7 71.4\%, PEB 87.5\%, DJI 81.8\%, BLE 70.3\%, KUG $100 \%$, DPP $75 \%$, DBS $76.9 \%$ ). No information about the remaining $19 \%$ was given in the databases.

Evaluation For $73.1 \%$ of all projects the databases show that an evaluation of data was realized or will be realized in the near future (BZgA 86.7\%, AG7 71.4\%, PEB 62.5\%, DJI $81.8 \%$, BLE $62.9 \%$, KUG $100 \%$, DPP $58.3 \%$, DBS $61.5 \%)$. A quarter $(24.1 \%)$ of the projects neither give information about the realization of the projects nor a possible evaluation. The database KUG indicates the evaluation of all kindergarten projects $(100 \%)$. The $\mathrm{BZgA}$, as well, notes that 26 of 30 projects are to be evaluated.

\section{Discussion}

Based on the addressed criteria, recommendations for the implementation of universal and selective projects will be given.

Universal and selective prevention In total, more than half of the projects $(56.7 \%, 44$ in total) taken into account target the level of selective prevention. This means that particularly socially deprived families or families with migration background are involved. Of the projects, $42.3 \%$ (33 in total) were identified as universal projects. Due to the fact that only 78 universal and selective projects could be found in the databases, we recommend an augmentation of these projects for the future.

Recent studies indicate that universal and selective projects can be promising in order to stabilize the level of obesity in the population, and might be helpful to reduce the prevalence of obesity, especially if socially deprived groups are addressed (Stice et al. 2006; Summerbell et al. 2005; Müller et al. 2001; Davis and Christoffel 1994).

Families with low SES and migration status The prevalence of overweight and obese children from families with low income and a low occupational status as well as from families with migration status is greater than in families with higher SES (Kurth and Schaffrath Rosario 2007; World Health Organization 2006b). This finding summarizes the necessity of establishing and extending intervention projects with special regard to this group. Fifty-eight of all projects $(\mathrm{N}=78)$ indicate that parents and children with low SES and migration status are targeted for involvement in the program. No information is given as to whether they participate or not. Especially the databases of the BZgA and BLE endeavor to shed light on the participation of socially deprived groups in health-related prevention projects.

Parental participation Interventions that intend to address families and especially those that involve socially deprived groups seem to be sensible in the kindergarten setting (National Institute for Health and Clinical Excellence 2006b; World Health Organization 2006b 2006c). Parental involvement should not only be considered at the development stage of the project, but also during the process evaluation (Hassel and Keimer 2008).

According to our criteria, parental participation is required in almost all of the projects (95\%) taken into account. No statements can be made here as to whether or 
not parents are adequately involved. Especially for socially deprived parents who cannot be reached easily, it has to be assured that the content and form of the address are adequately adopted so as to increase acceptance and motivation. Whether these attempts will be realized or not, and whether these attempts are of high or low quality, cannot be revealed here.

Target criteria and quality management To assure the success of projects, the criteria of the level of prevention, quality management with participative proceedings as well as good practice criteria and measurable, long-dated prevention goals should be the aspiration [Wright 2006; Kolip 2006; Deutsche Arbeitsgemeinschaft für Epidemiologie (DAE) 2004]. Our findings show that most of the projects (68\%) provide specific criteria for objectives as well as a written concept (74\%). Due to missing information in the databases, no statements can be made on specific contents of the projects included in our analysis.

Duration of projects It is advantageous to ensure a longterm continuation of the project as long as sustainability of the projects and health-promoting structures can be established. Interestingly, no information is available in the databases on how project sustainability can be ensured.

Manuals/materials In order to get detailed instructions about conducting the project and to gain comparability of projects, manuals should be available for every project. Also materials that provide relevant educational objectives of the program should be available for all participants; $75.7 \%$ of the projects are following this advice. Only a few are using no manuals/materials (6.4\%).

There is no exact information available for all other projects $(35.9 \%)$.

The results show that a mandatory regulation concerning the use of manuals and materials does not exist and that no exact statements can be made due to missing information in the databases.

Documentation/ evaluation The project documentation and evaluation are important to gain crucial insight into the advantages and disadvantages of a program. Only a coherent concept of project documentation and evaluation can result in precise statements on the impact of a program (Bundeszentrale für gesundheitliche Aufklärung 2006).

In conclusion, the kindergarten setting seems to be suitable for the realization of lifestyle-related measures as well as structural aspects like measures of physical activity as well as food literacy (World Health Organization 2006b). In order to use the broad variety of structural and behavioral resources, one needs to develop and integrate preventive strategies in a sustainable and participatory way in the context of extensive quality management in the settings. The major challenge is the finding of access paths and especially successful cooperation with parents.

Furthermore, an exchange of best practice kindergarten projects with regard to universal and selective childhood obesity prevention should be promoted. Considering this, mandatory criteria for the evaluation of those projects are missing. The databases taken into account in our study provide the possibility of getting a rough overview of the projects supplied. However, they are less indicative concerning the identification of good and successful projects. The eight criteria used here from guidelines for targeted prevention constitute a first step. The objective for the future should be a coherent and mandatory guideline allowing for the assessment of universal and selective childhood obesity prevention programs. It should include kindergarten obesity prevention projects that target all children with special regard to children with a socially deprived background. Due to the fact that only 78 universal and selective prevention projects were identified in our analysis, the provided data document the poor quality of prevention programs in Germany. Most of the programs cannot really add to our current knowledge about prevention projects and cannot provide a sound basis for future projects. There is need for future prevention projects to improve the quality of the projects, e.g., to augment the documentation in the databases in order to increase projects' transparency and comparability. Furthermore, systematic project evaluation seems of utmost importance in order to gain reliable data about the project's quality. For this purpose, mandatory criteria for the assessment of universal and selective prevention projects will be promising.

Acknowledgement The authors of the manuscript JOPH-D-0900011R1 entitled "What accounts for good-practice? Assessment of obesity prevention projects for kindergarten children in Germany" testify that there are no conflicts of interest.

Jessica A. Dreas and Holger Hassel

\section{References}

Böhm A, Friese E, Greil H, Lüdecke K (2002) Körperliche Entwicklung und Übergewicht bei Kindern und Jugendlichen. Analyse von Daten aus ärztlichen Reihenuntersuchungen des Öffentlichen Gesundheitsdiensts im Land Brandenburg [Physical development and overweight among children and youth. Analysis of data from mass examinations by the public health services of the German Federal State Brandenburg]. Monatsschr Kinderheilkd 150:48-57

Bundeszentrale für gesundheitliche Aufklärung (2005) Band 4: Qualitätskriterien für Programme zur Prävention und Therapie von Übergewicht und Adipositas bei Kindern und Jugendlichen [Quality criteria for programmes to prevent and treat overweight and obesity in children and adolescents]. Qualitätsraster für Präventionsmaßnahmen für übergewichtige und adipöse Kinder und Jugendliche. BZgA, Köln 
Bundeszentrale für gesundheitliche Aufklärung (2006) Band 5: Kriterien guter Praxis in der Gesundheitsförderung bei sozial Benachteiligten [Criteria of Good Practice in Health Promotion among Socially Disadvanted Individuals]. Ansatz-BeispieleWeiterführende Informationen. 2. erweiterte und überarbeitete Auflage. BZgA, Köln

Children environment and health (KUG) (2008) http://www.kinder umweltgesundheit.de (accessed 20 November 2008)

Davis K, Christoffel KK (1994) Obesity in preschool and school-age children. Treatment early and often may be best. Arch Pediatr Adolesc Med 148:1257-1261

Deutsche Arbeitsgemeinschaft für Epidemiologie (DAE) (2004) Leitlinien und Empfehlungen zur Sicherung von Guter Epidemiologischer Praxis (GEP) [Guidelines and Recommendations for Ensuring Good Epidemiological Practice (GEP)]. AG Epidemiologische Methoden der Deutschen Arbeitsgemeinschaft für Epidemiologie, Münster

Faeh D (2006) Die vom Mensch gestaltete Umwelt als Gesundheitsdeterminante. Die Struktur der Übergewichtsepidemie [The built environment as a health determinant. The structure of the obesity epidemic]. Schweiz Arzteztg 87:1453-1458

Federal Agency for Agriculture and Food (BLE) (2008) http://www. besseressenmehrbewegen.de (accessed 2 December 2008)

Federal Centre for Health Education (BZgA) (2008) http://www.gesund heitliche-chancengleichheit.de (accessed 20 November 2008)

Forschungsverbund Deutsches Jugendinstitut, Dortmunder Arbeitsstelle Kinder- und Jugendhilfestatistik (2008) Zahlenspiegel 2007 [The 2007 Data Mirror]. Kindertagesbetreuung im Spiegel der Statistik. Forschungsverbund DJI Universität Dortmund, Dortmund

German Education Server (DBS) (2008) http://www.bildungsserver.de (accessed 25 November 2008)

German Prevention Award (DPP) (2008) http://www.deutscher-praeven tionspreis.de (accessed 2 December 2008)

German Youth Institute (DJI) (2008) http://www.dji.de (accessed 4 December 2008)

Gill TP (1997) Key issues in the prevention of obesity. Br Med Bull 53:359-388

Hassel H, Keimer K (2008) Parent involvement when developing health education programmes. Ital J Public Health 5:4-11

Health Targets Germany: Working Area 7 (AG 7) (2008) http://www. gesundheitsziele.de (accessed 20 November 2008)

Kolip P (2006) Evaluation, Evidenzbasierung und Qualitätsentwicklung. Zentrale Herausforderungen für Prävention und Gesundheitsförderung [Evaluation, evidence and quality development. Major challenges of prevention and health promotion]. Präv Gesundheitsf 1:234-239

Kurth B-M, Schaffrath Rosario A (2007) Die Verbreitung von Übergewicht und Adipositas bei Kindern und Jugendlichen in Deutschland [The prevalence of overweight and obese children and adolescents living in Germany. Results of the German Health Interview and Examination Survey for Children and Adolescents (KiGGS)]. Bundesgesundheitsblatt Gesundheitsforschung Gesundheitsschutz 50:736-743

Müller MJ, Asbeck I, Mast M, Langnäse K, Grund A (2001) Prevention of obesity - more than an intention. Concept and first results of the Kiel Obesity Prevention Study (KOPS). Int J Obes Relat Metab Disord 25(Suppl 1):S66-S74

National Institute for Health and Clinical Excellence (2006a) Obesity: the prevention, identification, assessment and management of overweight and obesity in adults and children. NICE clinical guideline. (Rep. No. 43) NICE, London

National Institute for Health and Clinical Excellence (2006b) The effectiveness of interventions to prevent weight gain or maintain a healthy weight in children aged between 2 and 5 years. NICE, London

Platform Diet and Physical Activity (PEB) (2008) http://www. ernaehrung-und-bewegung.de (accessed 2 December 2008)

Prochaska JO, DiClemente CC (1982) Transtheoretical therapy: toward a more integrative model of therapy. Psychotherapy: Theory, Research and Practice 19:267-288

Prochaska JO, Redding C, Evens K (1996) The transtheoretical model of behaviour change. In: Glanz K, Lewis FM, Rimer BKH (eds) Health behaviour and health education: theory, research and practice. Jossey-Bass, San Francisco, CA

Scottish Intercollegiate Guidelines Network (1996) Obesity in Scotland: integrating prevention with weight management. Pilot Edition, Sign publication 8. SIGN, Edinburgh, 1-75

Spitzenverbände der deutschen Krankenkassen (2008) Gemeinsame und einheitliche Handlungsfelder und Kriterien der Spitzenverbände der Krankenkassen zur Umsetzung von $\S 20$ Abs. 1 und 2 SGB V vom 21. Juni 2000 in der Fassung vom 10. Februar 2006 [Common and Standardised Fields of Action and Criteria of the Central Organisations of Health Insurances for the Implementation of $\S 20$ subpara 1 and 2 SGB V dtd June 21st, 2000 as amended by version dtd February 10th, 2006]. IKK Bundesverband, Bergisch Gladbach

Stice E, Shaw H, Marti CN (2006) A meta-analytic review of obesity prevention programs for children and adolescents: the skinny on interventions that work. Psychol Bull 132:667-691

Summerbell CD, Waters E, Edmunds LD et al (2005) Interventions for preventing obesity in children. Cochrane Database Syst Rev 1-70

Thomas PR (ed) (1995) Weighing the options: criteria for evaluating weight-management programs. National Academy Press, Washington D.C.

World Health Organization (2000) Obesity: Preventing and managing the global epidemic. WHO Technical Report Series. (Rep. No. 894) WHO, Geneva, 1-253

World Health Organization (2006a) Addressing the socioeconomic determinants of healthy eating habits and physical activity levels among adolescents. Based on the WHO/HBSC Forum meeting in Florence, 10.-11. March 2006. WHO/HBSC Forum 2006, Copenhagen

World Health Organization (2006b) Die Herausforderung Adipositas und Strategien zu ihrer Bekämpfung in der Europäischen Region der WHO [The challenge of obesity in the WHO European Region and the strategies for response]. Europäische Ministerkonferenz der WHO zur Bekämpfung der Adipositas Ernährung und Bewegung für die Gesundheit, Istanbul, 15.-17. November 2006. World Health Organization, Copenhagen

World Health Organization (2006c) Food and nutrition policy for schools. A tool for the development of school nutrition programmes in the European Region. Programme for Nutrition and Food Security, Copenhagen

Wright M (2006) Partizipative Qualitätssicherung und Evaluation für Präventionsangebote im Setting [Participative quality assurance and evaluation for prevention programs in settings]. In: Rosenbrock R, Bellwinkel M, Schröer A (eds) Primärprävention im Kontext sozialer Ungleichheit: Wissenschaftliche Gutachten zum BKKProgramm "Mehr Gesundheit für alle". Wirtschaftsverlag NW, Bremerhaven, pp 297-346 